\title{
2 Indicator-based assessment of wilderness quality in \\ 3 mountain landscapes
}

\section{Author details}

5 Radford, Sarah, Louise ${ }^{a}$; Senn, Josef ${ }^{a}$; Kienast, Felix ${ }^{\text {a }}$

6 a Swiss Federal Institute for Forest, Snow and Landscape Research WSL, Zürcherstrasse 111, 8903

7 Birmensdorf, Switzerland

8 Correspondence author: Sarah Radford, Swiss Federal Institute for Forest, Snow and Landscape

9 Research WSL, Zürcherstrasse 111, 8903 Birmensdorf, Switzerland, sarah.radford@wsl.ch

Declarations of interest: none

This document is the accepted manuscript version of the following article: Radford, S. L., Senn, J., \& Kienast, F. (2019). Indicator-based assessment of wilderness quality in mountain landscapes. Ecological Indicators, 97, 438-446. https://doi.org/10.1016/j.ecolind.2018.09.054

This manuscript version is made available under the CC-BY-NC-ND 4.0 1icense http://creativecommons.org/1icenses/by-nc-nd/4.0/ 


\section{Abstract}

Wilderness is vitally important ecologically, economically, socially and culturally, yet it continues to decline globally. Despite high human modification and fragmentation in European landscapes, studies assessing wilderness in Europe suggest the presence of substantial areas of wilderness in mountainous areas. Following a European resolution, the importance of remaining wilderness areas has recently been recognised and efforts towards mapping and protecting remaining wildernesses have increased.

The central Alps lie within Switzerland and have been identified in multiple studies as a potential wilderness hotspot in Europe. In this study we develop robust, objective indicators to quantify wilderness and apply them to Switzerland. The indicators account for varying perceptions of wilderness and were evaluated by experts. Assessing international expert opinion to define indicator weightings has not been carried out in similar studies in the past, but serves as a transparent, objective and reproducible approach.

The indicators identified high quality wilderness areas, mostly at higher elevations, and demonstrate a suitable method for assessing remaining wilderness areas in landscapes subjected to large modifications by human activities. The spatial distribution of wilderness in the case study region Switzerland suggest that it may play an important role in wilderness conservation in Europe. Our study provides essential baseline information for wilderness monitoring, planning and protection, upon which future studies can build. Above this it provides robust, objective and adaptable indicators for wilderness quantification, which can be implemented in other countries and across various spatial scales. The method can be adapted for other countries - through the use of local expert opinions to weight indicators, and regions - with the inclusion of further datasets.

\section{Keywords}

GIS-based wilderness mapping, Multiple-Criteria-Evaluation, Switzerland, wilderness, wilderness conservation 
60

\section{Introduction}

Wilderness areas provide critical refuges for rare plant and animal species (Sinclair, 2015), vital ecosystem services including carbon storage and sequestration (Luyssaert et al., 2008), and act as buffers to regulate the local climate (Martin \& Watson, 2016). Wilderness areas also offer a huge potential for education and research (Schwartz et al., 2016), and are important for national and cultural heritage. As such wilderness is valuable economically, ecologically, socially and culturally. On a global level wilderness areas are however in considerable decline (Watson et al., 2016, Sanderson et al., 2002) and human pressures on the environment are increasing (Venter et al., 2016).

European landscapes are largely transformed and fragmented (European Environment Agency/ Swiss Federal Office for the Environment (EEA/FOEN), 2011), due to a long history of human settlement, agriculture, and as a result of industrialisation and urbanisation. Yet Europe still exhibits some large areas free from infrastructure, which are host to native species and ecosystems (Fisher et al., 2010). With increasing demands on land to support an anticipated growing population (United Nations, 2015) these remaining wilderness areas are under threat. The importance of these remaining wilderness areas has been recognised, and is reflected in how wilderness has recently become an increasingly prevailing topic in politics and nature conservation legislation in Europe (Jones-Walters \& Čivić, 2010). In 2009 the European parliament adopted a resolution calling for improved protection, funding and promotion of wilderness areas (European Parliament resolution on wilderness in Europe, 2009). This placed wilderness on the political agenda in Europe. The resolution also led to the development of guidelines for wilderness management within the Natura 2000 system (European Union, 2013). Since the resolution, strategies have been developed in several European countries to promote and initiate wilderness protection. WildEurope a partnership of 18 agencies, NGOs and other institutions was formed to coordinate protection and restoration strategies and was formally accepted as part of this resolution (Fisher et al., 2010).

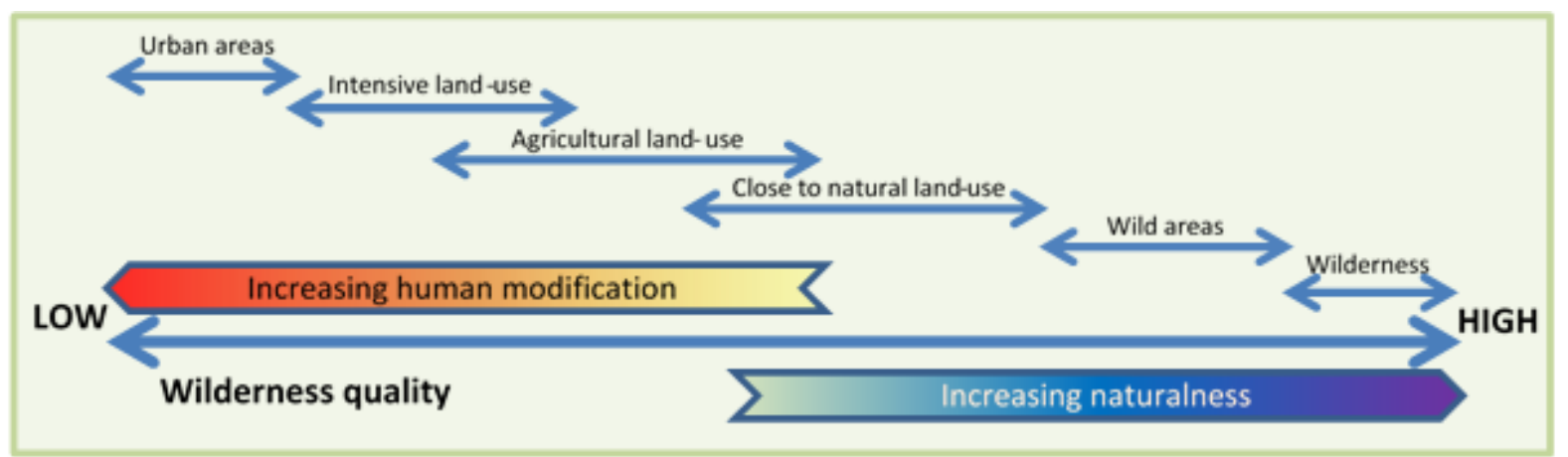

Figure 1. The wilderness continuum concept, adapted from Lesslie and Taylor (1985), shows wilderness at one end of a continuous scale ranging from high human modification to high naturalness. Wilderness is present at the most unmodified and most natural section of the scale. 
Wilderness is generally perceived as the most untouched, pristine natural areas. In context of today's European landscapes, wilderness lies at one extreme of a continuous gradient of naturalness (ranging from pristine nature to highly modified urban areas) (see Fig. 1). Beyond this unanimous defining character the meaning of the term 'wilderness' is very subjective and opinions on wilderness vary greatly depending on people's past experiences, encounters and expectations. Consequently a wide variety of definitions have been developed in different cultures and landscapes.

This study uses the following definition of wilderness:

"A wilderness is an area governed by natural processes. It is composed of native habitats and species, and large enough for the effective ecological functioning of natural processes. It is unmodified or only slightly modified and without intrusive or extractive human activity, settlements, infrastructure or visual disturbance. “ (European Union, 2013)

Recent pan-European mapping of wilderness indicates that the Central Alps may contain some significant remaining wilderness areas (Kuiters et al., 2013; EEA, 2010). Knowing the location of such areas is important for conservation (Mittermeier et al., 1998), the development of protected area networks (Belote et al., 2017; Locke \& Dearden, 2005) as well as for the management of present and future recreational activities. Despite a recent boost in studies and inventories of wilderness in Europe at the national scale (Plutzar, 2013; Ólafsdóttir \& Runnström, 2011; Müller et al., 2015), and in smaller regions and protected areas (Carver et al., 2002; Carver et al., 2012; Orsi et al., 2013) there is no comparable analysis or inventory of wilderness for Switzerland, an area that has repeatedly been mentioned to host remaining important wilderness areas. Moreover, there is a distinct need for robust and suitable indicators to evaluate and map wilderness, in order to identify remaining wilderness areas and to provide essential baseline information for wilderness monitoring, planning and protection.

The aims of this study are to:

1. Develop suitable and objective indicators, which account for varying wilderness perceptions, to quantify and map wilderness quality.

2. Identify areas of current high wilderness quality in the test region (Switzerland) using these indicators.

3. Demonstrate a robust method with suitable indicators, which may be applied in other geographical regions. 


\section{2. Materials and methods}

\subsection{Conceptual approach: the four wilderness indicators}

Wilderness quality was quantified based on four main criteria, here termed wilderness indicators, similar to studies of Carver et al. (2012), Carver et al. (2013) and Müller et al. (2015). The four wilderness indicators refer to main properties wilderness is considered to have:

Naturalness - A wilderness is an area of pristine nature, expected to comprise of native flora and fauna. Naturalness addresses the relevant biological properties of an area.

Human impact - A wilderness should be as free as possible from traces of people, including infrastructure, settlements, light and noise pollution.

Remoteness - Wilderness is generally far from civilisation and not easily accessible. Through this quality wilderness provides refuges for species particularly sensitive to human disturbance, and also the opportunities for solitude and reflection that visitors may seek.

Ruggedness - Ruggedness is a measure of the terrain and is particularly relevant in mountainous landscapes. Ruggedness can be perceived as a measure of a visitors' perception of wilderness, however it also plays a biological role in terms of speciation as incredibly challenging terrain may present barriers to gene-flow for certain species, but also provide refuges in secluded habitat for others.

Wilderness quality was modelled using quantitative data for these four indicators (see Fig. 2). The wilderness indicators (and their input data layers) may vary in their individual impacts on wilderness. This variation was accounted for through the combination of certain input data layers and wilderness indicators via weighted linear summation. Weights were applied according to expert opinions on the importance of these elements (data layers and indicators) for wilderness. Implementing expert opinion was considered to result in a more objective and accurate assessment of wilderness quality, than arbitrary weight assignment or equal weightings. Assessing international expert opinion to define weightings has not been carried out in similar studies in the past, but serves as a transparent, objective and reproducible approach. 


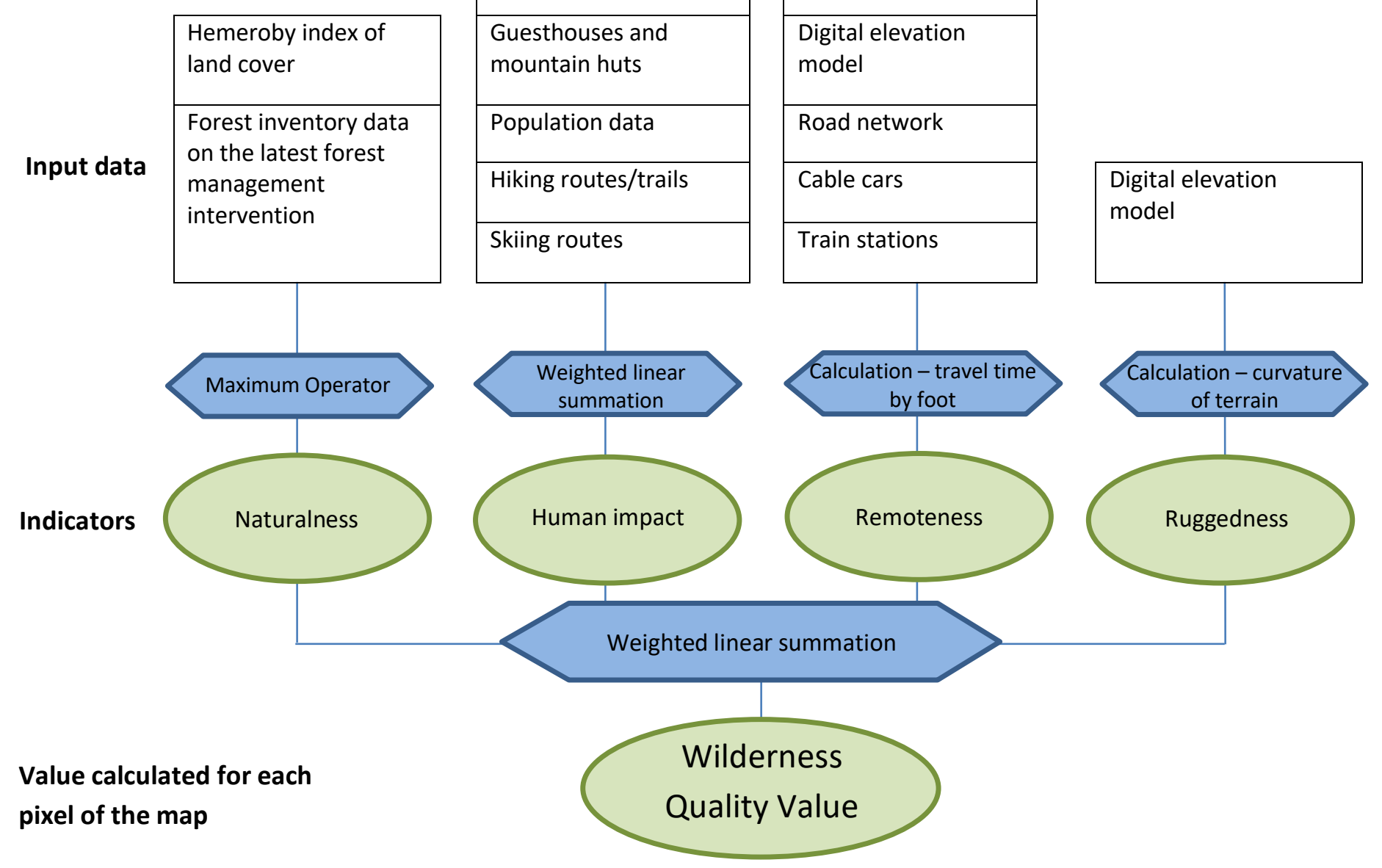

120 Figure 2. Overview of methods and dataflow. Input data to quantify the four wilderness indicators (naturalness, human 121 impact, remoteness and ruggedness) were compiled for the whole of Switzerland at a resolution of $1 \mathrm{ha}(100 \times 100 \mathrm{~m})$. 122 Hexagons indicate procedures applied to input data and wilderness indicators. Each pixel $(100 \times 100 \mathrm{~m})$ was assigned a 123 wilderness quality value based on the assimilation of values for each indicator; these were scaled, weighted and combined 124 to produce a wilderness quality value, resulting in a wilderness quality map. (Further information on input data available in 125 Table A. 2. in Appendix)

126 The size of the areas of high quality wilderness identified was considered in the results. Wilderness 127 areas should be large enough to support ecosystem functioning and natural processes. This study 128 considers areas of $\geq 3000$ ha, the minimum size for wilderness according to WildEurope (2013), and $129 \geq 1000$ ha, the lowest size category for consideration on the European wilderness quality standard 130 and audit system (European Wilderness Society, 2016) when comparing maps. 
132 To weight the data elements and indicators in order to combine them to produce an objective map

133 of wilderness quality, an expert survey was carried out. 25 experts, from five European countries,

134 who work in wilderness related fields were sent a survey. Survey questions aimed to investigate the

135 importance of individual input data elements and of the wilderness indicators in the professional

136 opinion of experts.

\subsubsection{Indicator combination}

138

The wilderness indicators were tested for correlations, prior to combination, to ensure that no particular aspect was overrepresented in the model. Tests for correlation were carried out with Spearman's rank in R Version 3.3.0 (The R Foundation for Statistical Computing, 2016) using the "cor" function in the package "stats". Wilderness indicators were subsequently normalised to a scale of 1 - 5 using natural breaks. The indicators "naturalness" and "human impact" were normalised inversely, as high values for these indicators corresponded to low wilderness quality. Combination was then carried out using weighted linear summation, with the following formula:

$$
W_{i}=\sum_{j=1}^{n} G_{i j} X_{i j}
$$

Where $W_{i}$ is the value for wilderness quality value for the $i$ th iteration, $j$ is the current wilderness indicator's number, $G$ is indicator weight and $X$ is the standardized value of each indicator (value on the normalised scale, see above), $n$ is the number of indicators.

Spatial analysis was carried out in geographical information system ArcMap 10.4.1. Data were converted to raster format, with pixel size $100 \times 100$ m. Calculations were carried out in ArcMap 10.4.1 and in IDLE Python GUI version 2.7.8 (Python software foundation).

\subsection{Test region}

Switzerland is a central European country with an area of ca. 41, $285 \mathrm{~km}^{2}$ (Swiss Federal Statistical Office, 1997). It is characterised by a highly variable climate and topography, featuring densely populated areas in the lowlands and remote areas in the mountains. It can be divided into 5 biogeographical regions; the Jura mountains, central plateau, northern Alps, central Alps and southern Alps (Gonseth et al., 2001). 


\subsection{Quantifying the wilderness indicators in the test region}

159

160

161

162

163

164

165

166

167

168

169

170

171

172

173

174

175

176

177

178

179

180

181

182

183

184

185

186

187

\subsubsection{Naturalness}

Naturalness is considered in terms of the degree of deviation in the composition of species and habitats from what would be expected to naturally occur in a particular area. In the absence of comprehensive data on vegetation, high resolution land cover data were reclassified to a hemeroby scale, similar to Plutzar, (2013) and Carver et al. (2013) and used to quantify naturalness. Values of the hemeroby scale ranged from 1 representing very close to natural conditions (ahemerobic) to 5 , highly modified and completely unnatural conditions (metahemerobic).

Forests and grasslands were further subdivided into three elevation categories (colline-montane, subalpine and alpine) and assigned hemeroby values accordingly (see Table A. 1. in appendix), respecting their different management and use intensities at different elevations. Elevation levels were calculated based on the timberline definition using $9.5^{\circ} \mathrm{C}$ July isotherms (Zimmerman \& Kienast, 1995). The intensity of forest management was also considered in the quantification of naturalness. For the test region Switzerland forest inventory data were used to identify forest areas where the last management action took place over 50 and over 100 years ago respectively. Data layers were combined using maximum operator, the higher value for naturalness was retained where layers overlapped.

\subsubsection{Human impact}

Actions to modify and manage landscapes, along with constructions and infrastructure degrade wilderness quality. In this study human features were evaluated to most accurately represent their impact, e.g. noise emitted from roads and railways was incorporated into the model, rather than just assessing the visibility of such artefacts or using Euclidean buffers to simulate their impact. Anthropogenic impacts were considered in several forms. Areas were categorised according to the degree to which they are free from infrastructure at a $500 \times 500 \mathrm{~m}$ resolution (Kienast et al., 2015). Infrastructure was assessed in three classes: completely free, where $0 \%$ of the $500 \times 500 \mathrm{~m}$ area was covered with a structure, minimal infrastructure $=0-5 \%$ and considerable infrastructure $>5 \%$.

Roads and railway lines cover a considerable amount of the land area and are a source of noise. Several studies and reviews indicate that noise (pollution) has negative effects on both people (Basner et al., 2014; Munzel et al., 2014) and wildlife (Benitez-Lopez et al., 2010; Barber et al., 2010; Barber et al., 2011). Based on guidelines for noise thresholds at night (World Health Organization, 
2009) average daily noise over the threshold of $30 \mathrm{~dB}(\mathrm{~A})$ was considered to have a negative impact on wilderness, noise data were thus categorised 0, 0-30 and $>30 \mathrm{~dB}(\mathrm{~A})$.

190

191

192

193

194

195

196

197

198

199

200

201

202

203

204

205

206

207

208

209

210

211

212

213

214

215

216

217

218

219

According to the wilderness definition used in this study, a wilderness is an area where people do not reside, but are visitors. To identify areas without human habitation, or with the least human habitation, population data were evaluated. Data were reclassified according to conservative parameters, 0 inhabitants, 1-10 and over 10 inhabitants. One effect of human settlements on the landscape is light pollution. Although only apparent at night, light pollution is known to negatively affect several wildlife species (Navara \& Nelson, 2007). A recent review by Gaston et al., (2013) highlighted the significant impact low levels of anthropogenic light pollution can have on wildlife, ecosystems and humans. Data on light pollution from the periods 1992-1994 and 2010-2012 were compared. Darkness was defined as complete darkness, i.e. radiance $=0$, where radiance $>0$ areas were considered "light". The entire test area was then classified according to these data and whether areas were dark in both periods, became light or were light in both time periods.

Other infrastructure was also taken into account. Guesthouses and huts were buffered by $200 \mathrm{~m}$ to more accurately represent their effect on immediately surrounding areas. Although hiking trails do not present barriers to the majority of wildlife, hiking itself is considered a disturbance in wilderness (Cole \& Landres, 1996), and is known to result in changes to vegetation (Pickering \& Hill, 2007). The effect of hiking trails and ski routes was assessed based on the length of trail or route in a $100 \times 100$ $m$ area. Landscape fragmentation was additionally incorporated into the model. Areas were assigned values based on the size of the patch containing no fragmenting structures, including among other things; settlements, roads, motorways and railways as fragmenting structures.

\subsubsection{Remoteness}

Remoteness is essential for one function often assigned to wilderness; that such areas should protect and maintain species, particularly species highly sensitive to human presence and disturbance and those which can be harmful to humans (Aplet et al., 2000). Remoteness, however, also describes the opportunity for solitude which some visitors may seek in wilderness (Boller et al., 2010). Remoteness was calculated in two steps, considering accessibility by foot and road and accessibility using public transport.

The time required to reach each pixel of the map was calculated from pixels with a minimum of 15 residents. Barriers such as slopes over $45^{\circ}$, rivers, large water masses and glaciers were taken into account (as in Carver et al., 2013) and walking speed was adapted according to land cover, based on assumptions from similar studies (Lieskovský et al., 2014; Carver et al., 2012). A walking speed of 4.2 
$\mathrm{km} / \mathrm{h}$ was taken for calculations on flat ground (Schweizer Wanderwege, 2015), changes in elevation were accounted for with additional walking time. Calculations were based on an extra 30 minutes walking time per consecutive slope increment, slope increments corresponded to a $300 \mathrm{~m}$ elevation change at velocity $4.2 \mathrm{~km} / \mathrm{h}$. A conservative travel speed of $30 \mathrm{~km} / \mathrm{h}$ was applied to roads to represent travel in cars (here roads considered were all $>3 \mathrm{~m}$ wide) the same speed was applied for cable cars (see Table 1).

All train stations situated more than $200 \mathrm{~m}$ from the nearest road were assumed only accessible via public transport. These stations were all assigned a standard accessibility time of 30 minutes, from pixels on the map with more than 15 inhabitants, due to the outstanding public transport system in Switzerland. Stations situated within $200 \mathrm{~m}$ of a road were not considered, as travel with a private vehicle to such points is generally quicker. Both components of remoteness were combined and the shorter travel time was taken to generate conservative values for remoteness.

\subsubsection{Ruggedness}

The calculation for ruggedness (as in Müller et al., 2015) followed Carver et al. (2012). Standard deviation of the curvature of terrain within a $250 \mathrm{~m}$ radius was calculated for the whole of Switzerland based on high resolution digital elevation model data. It is generally assumed that people perceive an area of ca. $250 \mathrm{~m}$ radius of their surroundings (Carver et al., 2012).

Table 1. The expected speed of movement over different land cover types, with their associated costs for movement through a $100 \mathrm{~m}$ pixel. Calculations were based on a walking speed of $4.2 \mathrm{~km} / \mathrm{h}$ on flat ground (Schweizer Wanderwege, 2015). Slopes were taken into account with an additional 30 minutes walking time per consecutive slope increment. Slope increments corresponded to $300 \mathrm{~m}$ change in elevation at velocity $4.2 \mathrm{~km} / \mathrm{h}$.

\begin{tabular}{|c|c|c|c|c|c|c|}
\hline \multirow[t]{2}{*}{ Landcover type } & \multirow{2}{*}{$\begin{array}{l}\text { speed } \\
(\mathrm{km} / \mathrm{h})\end{array}$} & \multicolumn{5}{|c|}{ Movement costs for $100 \mathrm{~m}$} \\
\hline & & $0-4^{\circ}$ gradient & $4-8^{\circ}$ gradient & $8-12^{\circ}$ gradient & $12-16^{\circ}$ gradient & $>16^{\circ}$ gradient \\
\hline Paths/trails & 4 & 86 & 128 & 170 & 210 & 247 \\
\hline $\begin{array}{l}\text { Background } \\
\text { landscape }\end{array}$ & 3.5 & 102 & 154 & 204 & 251 & 297 \\
\hline Forest & 3 & 120 & 180 & 238 & 293 & 346 \\
\hline $\begin{array}{l}\text { Dense, scrubby } \\
\text { vegetation }\end{array}$ & 2 & 181 & 269 & 356 & 440 & 519 \\
\hline Water & & & & Barrier & & \\
\hline Roads & 30 & 12 & 12 & 12 & 12 & 12 \\
\hline Cable cars & 30 & 12 & 12 & 12 & 12 & 12 \\
\hline
\end{tabular}




\section{Results}

\subsection{Expert survey}

24422 experts responded to the survey, responses were evaluated collectively giving average (median)

245 importance ratings for each of the four wilderness indicators and the data elements upon which

246 their quantification was based. Weights for the four wilderness indicators and data elements for „human impact“ were calculated based on these importance ratings (see Tables $2 \& 3$ ). Weightings were calculated as follows:

$$
G_{i}=I R / \frac{\sum_{I R=1}^{n} I R}{n}
$$

249

Where $G_{i}$ is the weighting, $I R$ is the importance rating (median), and $n$ is the number of wilderness indicators (Table 2) or the number of input data layers (Table 3 ) to be weighted. The median importance rating of all experts and the corresponding weightings are visible in Tables $2 \& 3$. In order to see how the weighting of the indicators and their input data layers can affect the wilderness quality map additional comparisons were carried out, using strongly contrasting weightings to those of the "collective expert opinion".

Table 2. Weights of the four wilderness indicators, weightings based on responses to the survey question „In your professional opinion how important would you rate the following indicators for wilderness? (1 - not important at all, 10 very important) “. Importance ratings are median values of expert responses $(n=22)$.

\begin{tabular}{lcc}
\hline Wilderness indicator & \multicolumn{2}{c}{ Collective expert opinion $(\mathrm{n}=22)$} \\
& Importance rating (IR) & Weighting $^{1}$ \\
\hline Naturalness & 8 & 1.07 \\
Human impact & 9 & 1.20 \\
Remoteness & 8 & 1.07 \\
Ruggedness & 5 & 0.67
\end{tabular}

\footnotetext{
${ }^{1}$ Formula: IR/SUM (IR)* number of wilderness indicators
} 
Table 3. Weights of the individual elements which contribute to the indicator "human impact". Weightings based on the responses of experts regarding the importance of individual data elements of this indicator. Importance ratings are median values of expert responses $(n=22)$.

\begin{tabular}{lcc}
\hline Input data layer & \multicolumn{2}{c}{ Collective expert opinion $(\mathrm{n}=22)$} \\
& Importance rating (IR) & Weighting \\
\hline Noise from roads & 9 & 1.29 \\
Noise from trains & 9 & 1.29 \\
Light pollution & 5 & 1.14 \\
Huts & 7 & 0.71 \\
Guesthouses & 3.5 & 1.00 \\
Hiking routes & 3.5 & 0.50 \\
Skiing trails & & 0.50 \\
$\begin{array}{l}\text { Structures in the } \\
\text { landscape }\end{array}$ & 9 & 1.29 \\
$\begin{array}{l}\text { Fragmentation of the } \\
\text { landscape /barriers in } \\
\text { the landscape }\end{array}$ & 9 & 1.29 \\
$\begin{array}{l}\text { High population in } \\
\text { surrounding area }\end{array}$ & &
\end{tabular}

\subsection{Wilderness maps for the test region Switzerland}

Maps of the individual wilderness indicators (Fig. 3) show several similar areas to be valuable in terms of the aspects of wilderness they represent. Mountainous regions of the Alps were identified by all indicators as valuable. Despite some spatial overlap when visually assessing the wilderness indicators (Fig. 3) they were not considered collinear, rho < 0.7 (Dormann et al., 2013) (see Table 4).

Table 4. Matrix of Rho values from Spearman's rank correlation test, all values for rho $<0.7$ which is the threshold identified by Dormann et al. (2013) above which collinearity begins to distort model estimations.

\begin{tabular}{lcccc}
\hline Indicator & Naturalness & Human impact & Remoteness & Ruggedness \\
\hline Naturalness & -- & 0.469 & -0.651 & -0.020 \\
Human impact & 0.469 & -- & -0.662 & 0.037 \\
Remoteness & -0.651 & -0.662 & -- & -0.140 \\
Ruggedness & -0.020 & 0.037 & -0.140 & --
\end{tabular}

The wilderness quality map for Switzerland weighted according to all experts (Fig. 4) indicates areas of high wilderness quality at higher elevations in the Alps, with areas of very high wilderness quality over the Aletsch glacier, in small areas in south-eastern Switzerland on the boarder to Italy and in valleys in western Switzerland on the boarder to Italy. Some of the road network is recognisable in southern Switzerland, as areas in the red to red-orange range. In the central plateau it is not possible

\footnotetext{
${ }^{2}$ Formula: IR/SUM (IR)* number of input data layers
} 
274 from the map to identify many individual cities, which demonstrates the impact of land cover and

275 infrastructure on the model.

276 When quantified according to collective expert opinion (Fig. 4) 23,915 ha of Switzerland lie within

277 the top $10 \%$ wilderness quality (wilderness quality value $\geq 19$ ), comprising an area of ca. $0.6 \%$ of the

278 Swiss territory. However no patches of this high wilderness quality form areas large enough to be

279 recognised as wilderness according to the size definition of WildEurope ( $\geq 3000$ ha) or the lowest

280 size defined by European Wilderness Society ( $\geq 1000 \mathrm{ha}$ ). The patches of highest wilderness quality

281 value are scattered and do not form continuous segments. Areas within the top $25 \%$ of wilderness quality (wilderness quality values $16-20$ ) constitute ca. $12 \%$ of the land area, of which 384,502 ha (9\% of the total land area) are comprised of areas over 3000 ha in size and 22 areas covering 35,619 ha represent wilderness areas over 1000 ha in size.

An additional comparison was carried out between wilderness maps derived from collective expert weightings of input parameters and maps based on strongly differing weightings to identify where differences may lie. Despite distinct differences, there was general agreement concerning the areas of highest wilderness quality. This indicates that the method, particularly the combination of indicators via weighted summation, is robust (as general patterns remain present despite differences in weightings).

Table 5. Overview of wilderness quality as weighted by collective expert opinion, here the total land area covered by the upper $10 \%$ and $25 \%$ wilderness qualities are shown: wilderness quality values $\geq 19$ represent the upper $10 \%$ wilderness quality and $\geq 16$ the upper $25 \%$ wilderness quality. The area covered by patches which meet the size definitions 1000 ha and 3000 ha are also shown.

\begin{tabular}{ccccc}
\hline $\begin{array}{c}\text { Wilderness } \\
\text { quality } \\
\text { value }\end{array}$ & $\begin{array}{c}\text { Area } \\
\text { covered } \\
\text { (ha) }\end{array}$ & $\begin{array}{c}\text { Collective expert opinion } \\
\text { national } \\
\text { territory }\end{array}$ & $\begin{array}{c}\text { Area } \\
\text { covered } \\
\text { by } \\
\text { patches } \\
\geq 1000 \text { ha }\end{array}$ & $\begin{array}{c}\text { Area } \\
\text { covered } \\
\text { by } \\
\text { patches } \\
\geq 3000 \text { ha }\end{array}$ \\
\hline$\geq 19$ & 23914 & 0.6 & 0 & 0 \\
$\geq 16$ & 531864 & 12.8 & 35619 & 384502
\end{tabular}


Figure 3. Maps of wilderness indicators, a) Naturalness - on a scale of 1-5, where 1 represents the most natural and 5 the most modified and unnatural areas, b) Human impact - on a scale of 1-5, where 5 represents areas with the highest human impact and 1 areas with very low human impact, c) Remoteness - displayed in terms of accessibility from the nearest considerably populated area (< 15 residents), darker areas indicate lower accessibility and higher remoteness and d) Ruggedness - map depicts the ruggedness of the terrain in 5 levels, 5 represents high ruggedness, 1 low ruggedness.

Figure 4. Wilderness quality in Switzerland based on the four indicators; „naturalness“, „,human impact", „remoteness" and „ruggedness“, weighted according to expert opinion (n=22).

Wilderness quality is shown on a continuous scale, where dark blue areas represent areas with the highest wilderness quality, and red areas with the lowest wilderness quality. 


\section{Discussion}

304

305

306

307

308

309

310

311

312

313

314

315

Wilderness is a highly valuable resource due to its multiple functions and services, yet it may be threatened by future human development. As such the assessment and quantification of wilderness quality is vital to enable its future protection.

The method of wilderness quantification presented in this study, although similar to that of Carver et al., (2013) and Müller et al., (2015) differs in the quantification and combination of indicators. The wilderness indicators implemented in this study are considered scientifically justifiable, reliably quantified and, as their quantification is based on existing datasets, their implementation is cost effective and applies accurately to large areas. Results of this study identified areas of high wilderness quality in Switzerland, most of which were present at higher elevations in mountainous areas. The spatial distribution of wilderness in this study concurs with results of studies in topographically similar landscapes (Carver et al., 2012) and studies addressing larger spatial scales (European Environment Agency, 2010; Kuiters et al., 2013). This indicates a high level of confidence in the maps produced and robustness in the data and methods implemented.

The wilderness map of the test region derived from collective expert weightings of the input parameters (Figure 4.) was additionally compared to wilderness maps created using strongly differing weightings to see where differences may lie. In comparing these maps it became clear that whilst distinct differences were visible there was agreement between the maps concerning the pattern of areas of highest wilderness value. This indicates that the method, particularly the combination of indicators via weighted summation, is robust (as general patterns remain present despite differences in weightings). The method is therefore considered suitable for adaptation; weighting of the indicators and input data elements could be adapted according to surveys of regional experts. In this way the method used in this study could be applied in other countries, where perceptions of the importance of wilderness indicators may vary, or where different elements may play stronger or weaker roles in the landscape.

We state that the methods could be applied in other geographical areas or ecoregions, and suggest here some adaptations to the methods to make them suitable for different topographical regions. Ruggedness (the degree of variation in elevation within a particular area) is the least universal indicator, as it requires rich topography. It is considered a proxy for the roughness and heterogeneity of habitats in mountainous areas. The higher their roughness and heterogeneity, the more likely the presence of original flora and fauna and thus wilderness, and the greater the human perception of wilderness. When analysing the wilderness quality of areas with less mountainous 
terrain, this indicator could be removed from the model and the weights of the other indicators could be re-assessed accordingly. By removing the indicator ruggedness it would still be possible to quantify the main components of wilderness. Alternatively "ruggedness" could be substituted by an equivalent indicator which measures roughness and heterogeneity of habitats. For an ecoregion, such as arctic tundra this could be the spatial arrangement of solid ground and wetlands. For certain contexts, the indicator remoteness may be questioned as well. Remoteness measures the degree to which an area is accessible by humans and assumes that easily accessible areas are more likely to be disturbed by humans than remote ones. As this is certainly true on a global scale (e.g. Antarctica), it might not necessarily hold for close-by pristine areas such as waterfalls, caves or other landscape elements, which are close to civilisation but have not been transformed either due to their low economic or high cultural or aesthetic value.

This study provides a firm basis upon which to build and refine the picture of wilderness for a test study in mountainous terrain. It also allows the inclusion of newer datasets within indicators in the future as they become available. The method used to quantify wilderness could be further developed through the inclusion of additional more detailed data sets. As noise pollution from roads and railways was considered in this study, future studies could assess additional sources of disturbance such as noise from industrial activities, which has been shown to affect the breeding success of songbirds (Habib et al., 2007). Occurrence data of mammal species were not implemented in the model as the available data are comprised mostly of chance observations or observation along trails and roads. Additionally there is room for debate as to which species are valid indicators of wilderness or wilderness quality (Ceauşu et al., 2015). This is a potential area for further investigation, but was not an aspect considered within the scope of this study.

Considering the results in context with other studies there is strong indication that mountainous regions are the areas which contain wilderness in heavily modified European landscapes. As a large part of the central Alps is situated in Switzerland and considerable amounts of this mountainous region have been identified to have high wilderness quality both in this study and also by Kuiters et al. (2013) and the European Environment Agency (2010), Switzerland may play an important role in central European wilderness conservation efforts in the future. Some areas of high wilderness quality identified lie on the country's border, for example several valleys in south-western Switzerland (southern Valais), Fig. 4. When these results are considered alongside the unfragmented areas of the Alps, as highlighted in a study by Kaissl (2002), they could significantly contribute to internationally important areas worthy of protection. 
Transboundary protected areas, protected areas which cross international boundaries (Vasilijević et al., 2015), allow the protection of larger areas than solely concentrating on single countries. As such they could be implemented to provide high quality wilderness areas with suitable protection at the scale at which it is required. Conserving large unfragmented areas is particularly important for protecting whole ecosystems and their functions, therefore promoting ecosystem resilience to climate change (Martin \& Watson, 2016). Moreover as wilderness areas are not confined to political boundaries, complementary mapping in neighbouring countries would be required to demarcate the high wilderness quality areas of conservation importance which cross international borders.

In order to assist practise (eg. Landscape planning and protection/conservation) the continuous scale of wilderness quality could be divided into categories of wilderness quality, however there is to date no scientific basis for setting thresholds for such categories. An additional map (See Appendix, Figure A. 1.) demonstrates a wilderness quality map with categories of wilderness quality rather than a continuous scale. Although this may be valuable as an overview to guide practice, the size of areas of high wilderness quality must be taken into account prior to any planning or protection development, as the size of connected areas of high wilderness quality is ecologically just as important as the quality itself. A connected network of different habitats can support long-term, viable metapopulations (Hanski, 2005), whereas fragmented areas mostly have small isolated populations. As such unfragmented wilderness areas are more valuable for conservation as the probability is higher that they support connected biotopes.

In order to assist practise (e.g. Landscape planning and protection/conservation) the continuous scale of wilderness quality could be divided into categories of wilderness quality. An additional map (See Appendix, Figure A. 2.) demonstrates a wilderness quality map with the highest wilderness qualities divided into categories rather than on a continuous scale. Although this may be valuable as an overview to guide practice in determining areas for conservation, the thresholds for category definitions are arbitrary and have no scientific bases. The size of connected areas of high wilderness quality are taken into account in this figure. This is crucial as a connected network of different habitats can support long-term, viable meta-populations (Hanski, 2005), whereas fragmented areas mostly have small isolated populations. As such unfragmented wilderness areas are more valuable for conservation as the probability is higher that they support connected biotopes. Consequently the size of connected areas of high wilderness quality is just as important as the quality of these areas and must be taken into account prior to any planning or protection development. 
402 5. Conclusion

403

404

405

406

407

408

409

410

411

412

413

414

415

416

417

418

419

420

421

422

423

424

425

426

\section{Authors' Contributions}

428 developments. and communication.

This study provides a search strategy to identify the geographical locations of wilderness using four indicators. Three of the four indicators can be considered universal, i.e. applicable to a range of different ecoregions. One indicator (ruggedness) is relevant in the context of mountainous terrain but could be removed or replaced should the search strategy presented in this study be applied to topographically uniform terrain. The application of the methods to the test area Switzerland yielded a spatially explicit overview of wilderness quality at the national scale, and solid baseline data upon which further studies can build. The method could easily be applied in other countries, as comparable data sets to those used in this study are available in most European countries (Kuiters et al., 2013). Moreover the method is flexible and allows the opinions of local experts and or local people to be implemented in future assessments to define the weighting of data elements and wilderness indicators. The involvement of local people is invaluable for promoting the acceptance of regional developments and protected areas (Blondet et al., 2017).

The method developed in this study is also suitable for application in regional studies where it could include more detailed data (data available at a higher resolution than national data) for example on forest dynamics (i.e. deadwood, stand age and structure). Further studies could investigate the current protection status and future threat status of high quality wilderness areas identified in this study, using land-use change scenarios (e.g. Price et al., 2015) and information on planned

As concerns the test region, Switzerland has a role to play in European wilderness conservation. Conservation of suitably large areas will most likely take the form of transboundary protected areas. The straightforward and cost-effective approach presented in this study could be implemented to facilitate transboundary wilderness quality assessments and strengthen transboundary cooperation

SR, FK and JS conceived the ideas and designed methodology; SR and FK compiled the data; SR analysed the data; SR led the writing of the manuscript. All authors contributed critically to the drafts and gave final approval for publication. 


\section{Acknowledgements}

432

We would like to thank Sebastian Moos for vivid discussion on wilderness concepts, Mountain Wilderness, the Bristol Stiftung and the Swiss Federal Institute for Forest, Snow and Landscape Research WSL for financial support (funding sources had no involvement in study design, data collection, analysis or interpretation, nor the writing of this article). We are also very grateful to Gaëtan Palka for his assistance with python scripts. The study was embedded in a cooperative project with social scientists and the NGO Mountain Wilderness.

\section{References}

Aplet, G., Thomson, J. \& Wilbert, M. (2000) Indicators of wildness: Using attributes of the land to assess the context of wilderness. USDA Forest Service Proceedings, Ft Collins.

Barber, J.R., Crooks, K.R. \& Fristrup, K.M. (2010) The costs of chronic noise exposure for terrestrial organisms. Trends in Ecology and Evolution, 25, 180-189.

Barber, J.R., Burdett, C.L., Reed, S.E., Warner, K.A., Formichella, C., Crooks, K.R., Theobald, D.M. \& Fristrup, K.M. (2011) Anthropogenic noise exposure in protected natural areas: estimating the scale of ecological consequences. Landscape Ecology, 26, 1281-1295.

Basner, M., Babisch, W., Davis, A., Brink, M., Clark, C., Janssen, S. \& Stansfeld, S. (2014) Auditory and nonauditory effects of noise on health. The Lancet, 383, 1325-1332.

Belote, R.T., Dietz, M.S., Jenkins, C.N., McKinley, P.S., Irwin, G.H., Fullman, T.J., Leppi, J. C. \& Aplet, G.H. (2017) Wild, connected, and diverse: building a more resilient system of protected areas. Ecological Applications, 27, 1050-1056.

Benitez-Lopez, A., Alkemade, R. \& Verweij, P. A. (2010) The impacts of roads and other infrastructure on mammal and bird populations: A meta-analysis. Biological conservation, 143 (6), 1307-1316. DOI: 10.1016/j.biocon.2010.02.009

Blondet, M., de Koning, J., Borrass, L., Ferranti, F., Geitzenauer, M., Weiss, G., Turnhout, E. \& Winkel, G. (2017) Participation in the implementation of Natura 2000: A comparative study of six EU member states. Land use Policy, 66, 346-35. DOI: 10.1016/j.landusepol.2017.04.004

Boller, F., Hunziker, M., Conedera, M., Elsasser, H. \& Krebs, P. (2010) Fascinating Remoteness: The Dilemma of Hiking Tourism Development in Peripheral Mountain Areas. Mountain Research and Development, 30, 320-331.

Carver, S., Evans, A. J. \& Fritz, S. (2002) Wilderness attribute mapping in the UK. International Journal of Wilderness, 8, 24-29.

Carver, S., Comber, A., McMorran, R. \& Nutter, S. (2012) A GIS model for mapping spatial patterns and distribution of wild land in Scotland. Landscape and Urban Planning, 104, 395-409.

Carver, S., Tricker, J. \& Landres, P. (2013) Keeping it wild: mapping wilderness character in the United States. J Environ Manage, 131, 239-255. 
Ceauşu, S., Gomes, I. \& Pereira, H.M., (2015). Conservation Planning for Biodiversity and Wilderness: A RealWorld Example. Environmental Management, 55, 1168-1180.

Cole, D.N. \& Landres, P.B. (1996) Threats to wilderness ecosystems: Impacts and research needs. Ecological Applications, 6, 168-184.

Dormann, C.F., Elith, J., Bacher, S., Buchmann, C., Carl, G., Carré, G., Marquéz, J.R.G., Gruber, B., Lafourcade, B., Leitão, P.J., Münkemüller, T., McClean, C., Osborne, P.E., Reineking, B., Schröder, B., Skidmore, A.K., Zurell, D. \& Lautenbach, S. (2013) Collinearity: a review of methods to deal with it and a simulation study evaluating their performance. Ecography, 36, 27-46.

EEA (European Environment Agency), 2010. Europe's ecological backbone: recognising the true value of our mountains EEA Report No. 6, EEA: Copenhagen.

EEA/FOEN, 2011. Landscape fragmentation in Europe: Joint EEA-FOEN Report. EEA: Copenhagen.

European Parliament resolution of 3 February 2009 on Wilderness in Europe (2008/2210(INI)). European Parliament: Strasbourg.

European Union, 2013. Guidelines on Wilderness in Natura 2000 Management of terrestrial wilderness and wild areas within the Natura 2000 Network, European Union: Luxemburg.

European Wilderness Society, 2016. European Wilderness Quality Standard and Audit System [pdf] Available online at: <http://wilderness-society.org/european-wilderness-definition/european-wildernessquality-standard-audit-system/> [Accessed 03.04.2017]

Fisher, M., Carver, S. Kun, Z., McMorran, R., Arrell, K. and Mitchell, G. (2010). Review of Status and Conservation of Wild Land in Europe. Project commissioned by the Scottish Government

Gaston, K.J., Bennie, J., Davies, T.W. \& Hopkins, J. (2013) The ecological impacts of nighttime light pollution: a mechanistic appraisal. Biological Reviews of the Cambridge Philosophical Society, 88, 912-927.

Gonseth, Y., Wohlgemuth, T., Sansonnens, B., \& Buttler, A. (2001). Die biogeographischen Regionen der Schweiz. Erlaeuterungen und Einteilungsstandard. Bern: Bundesamt fuer Umwelt Wald und Landschaft.

Habib, L., Bayne, E.M., Boutin, S. (2007) Chronic industrial noise affects pairing success and age structure of ovenbirds Seiurus aurocapilla. Journal of Applied Ecology, 44,176-184

Hanski, I., 2005. The Shrinking World: Ecological Consequences of Habitat Loss. Oldendorf/Luhe, Germany: International Ecology Institute.

Jones-Walters, L. \& Čivić, K. (2010) Wilderness and biodiversity. Journal for Nature Conservation, 18, 338-339. Kaissl, T. (2002) Mapping the wilderness of the Alps: A GIS-based approach. Diploma thesis at the University of Vienna, Vienna.

Kienast, F., Frick, J., van Strien, M.J. \& Hunziker, M. (2015) The Swiss Landscape Monitoring Program - A comprehensive indicator set to measure landscape change. Ecological Modelling, 295, 136-150.

Kuiters A.T., van Eupen M., Carver S., Fisher M., Kun Z. \& Vancura V. (2013). Wilderness register and indicator for Europe - Final Report. European Commission.

Lesslie, R.G. \& Taylor, S.G. (1985) The Wilderness Continuum Concept and its Implications for Australian Wilderness Preservation Policy. Biological Conservation, 309-333. 
Lieskovský, J., Kenderessy, P., Špulerová, J., Lieskovský, T., Koleda, P., Kienast, F. \& Gimmi, U. (2014) Factors affecting the persistence of traditional agricultural landscapes in Slovakia during the collectivization of agriculture. Landscape Ecology, 29, 867-877.

Locke, H. \& Dearden, P. (2005) Rethinking protected area categories and the new paradigm. Environmental Conservation, 32, 1-10.

Luyssaert, S., Schulze, D., Börner, A., Knohl, A., Hessenmöller, D., Law, B.E., Ciais, P. \& Grace, J. (2008) Oldgrowth forests as global carbon sinks. Nature, 455, 213-215.

Martin, T.G. \& Watson, J.E.M. (2016) Intact ecosystems provide best defence against climate change. Nature Climate Change, 6, 122-124.

Mittermeier, R.A., Myers, N., Thomsen, J.B., da Fonseca, G.A.B. \& Olivieri, S. (1998) Biodiversity Hotspots and Major Tropical Wilderness Areas: Approaches to Setting Conservation Priorities. Conservation Biology, $12,516-520$.

Müller, A., Bøcher, P.K. \& Svenning, J.-C. (2015) Where are the wilder parts of anthropogenic landscapes? A mapping case study for Denmark. Landscape and Urban Planning, 144, 90-102.

Munzel, T., Gori, T., Babisch, W. \& Basner, M. (2014) Cardiovascular effects of environmental noise exposure. European Heart Journal, 35, 829-836.

Navara, K.J. \& Nelson, J.R. (2007) The dark side of light at night: physiological, epidemiological, and ecological consequences. Journal of Pineal Research, 43 (3), 215-224.

Ólafsdóttir, R. \& Runnström, M.C. (2011) How Wild is Iceland? Wilderness Quality with Respect to Naturebased Tourism. Tourism Geographies, 13, 280-298.

Orsi, F., Geneletti, D. \& Borsdorf, A. (2013) Mapping wildness for protected area management: A methodological approach and application to the Dolomites UNESCO World Heritage Site (Italy). Landscape and Urban Planning, 120, 1-15.

Pickering, C.M. \& Hill, W. (2007) Impacts of recreation and tourism on plant biodiversity and vegetation in protected areas in Australia. Journal of environmental management, 85 (4), 791-800.

Plutzar C. 2013. WWF Wildnis Modellierung Österreich - eine GIS-gestützte Analyse. (Technischer Bericht), World Wildlife Fund: Wien.

Price, B., Kienast, F., Seidl I., Ginzler, C., Verburg, P.H. \& Bolliger, J. (2015) Future landscapes of Switzerland: Risk areas for urbanisation and land abandonment. Applied Geography 57, 32-41.

Sanderson, E.W., Jaiteh, M., Levy, M.A., Redford, K.H., Wannebo, A.V. \& Woolmer, G. (2002) The human footprint and the last of the wild. Bioscience, 52, 891-904.

Schwartz, M.K., Hahn, B.A. \& Hossack, B.R. (2016) Where the Wild Things Are: A Research Agenda for Studying the Wildlife-Wilderness Relationship. Journal of Forestry, 114, 311-319.

Schweizer Wanderwege (2015). Schweizer Wanderwege: Karten und hilfsmittel. [online] Available at: <https://www.wandern.ch/de/wandern/vorbereitung/karten-und-hilfsmittel> [Accessed 10.06.17] Swiss Federal Statistical Office (SFSO), (1997). Statistisches Jahrbuch der Schweiz. Zürich: Verlag Neue Zürcher Zeitung. 
Sinclair, A.R.E. 2015. Protected areas are necessary for conservation. In: Wuerthner, G., Crist, E., \& Butler, T. (eds.) Protecting the Wild: Parks and Wilderness. The Foundation for Conservation, Island Press. United Nations, (2015). Department of Economic and Social Affairs, Population Division (2015). World Population Prospects: The 2015 Revision. United Nations, New York, USA.

Vasilijević, M., Zunckel, K., McKinney, M., Erg, B., Schoon, M., Rosen Michel, T., Groves, C., Phillips, A. (2015). Transboundary Conservation: A systematic and integrated approach. IUCN, 108 pp. DOI: 10.2305/IUCN.CH.2015.PAG.23.en

Venter, O., Sanderson, E.W., Magrach, A., Allan, J.R., Beher, J., Jones, K.R., Possingham, H.P., Laurance, W.F., Wood, P., Fekete B.M., Levy, M.A \& Watson, J.E.M (2016) Sixteen years of change in the global terrestrial human footprint and implications for biodiversity conservation. Nature Communications, 7(12558), 1-11. DOI: 10.1038/ncomms12558

Watson, J.E.M., Shanahan, D.F., Di Marco, M., Allan, J., Laurance, W.F., Sanderson, E.W., Mackey, B. \& Venter, O. (2016) Catastrophic Declines in Wilderness Areas Undermine Global Environmental Targets, Current Biology, 26, 1-6.

WildEurope (2013) A working definition of European wilderness and wild areas. [pdf] Available at: http://www.wildeurope.org/images/pdf/a-working-definition-of-european-wildernessand-wildareas.pdf [Accessed 02.04.17]

World Health Organization (WHO) (2009) Night Noise Guidelines for Europe, WHO: Copenhagen, Denmark. [pdf] Available at: <http://www.euro.who.int/_data/assets/pdf_file/0017/43316/E92845.pdf> [Accessed 05.12.16]

Zimmerman, N. \& Kienast, F. (1995) Das Klima lässt sich nicht kartieren - Klimakarten werden gerechnet. Informationsblatt des Forschungsbereiches Landschaft, 27, 1-3. 
Fig. 3
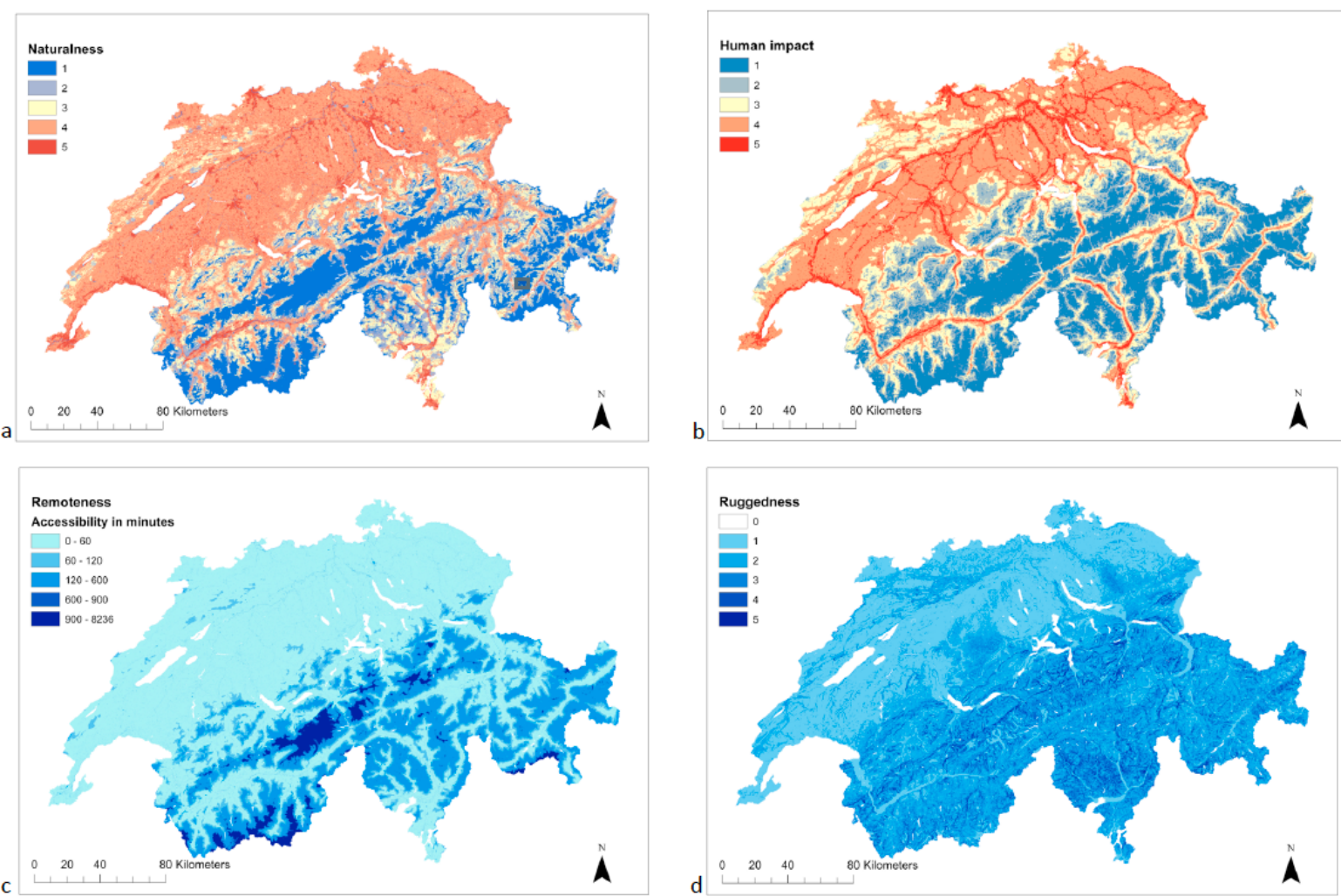
Fig. 4

Wilderness quality

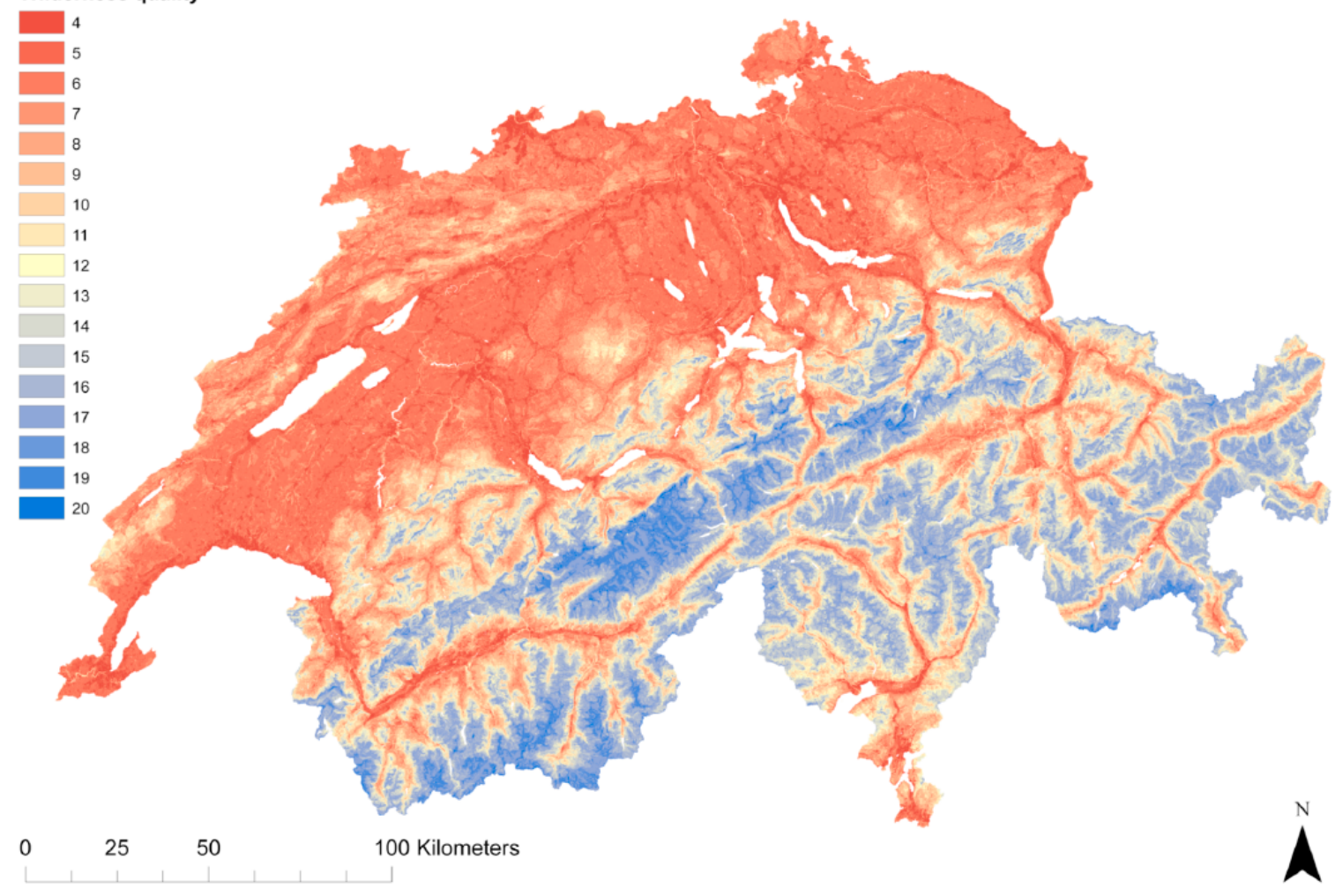

